\title{
ANALYSIS OF EXTREME BERYLLIUM-7 SPECIFIC ACTIVITIES IN SURFACE AIR*
}

\author{
Jelena Ajtići ${ }^{* *}$, Vladimir Djurdjevic3, Darko Sarvan', \\ Erika Brattich ${ }^{4}$, Miguel A. Hernández-Ceballos5
}

\author{
${ }^{1}$ Faculty of Veterinary Medicine, University of Belgrade, Belgrade, Serbia \\ ${ }^{2}$ Institute for Research and Advancement in Complex Systems, Belgrade, Serbia \\ 3Institute of Meteorology, Faculty of Physics, University of Belgrade, Belgrade, Serbia \\ 4Environmental Chemistry and Radioactivity Laboratory, Department of Chemistry "G. Ciamician", \\ Alma Mater Studiorum University of Bologna, Bologna, Italy \\ 5European Commission, Joint Research Centre, Institute for Transuranium Elements, \\ Nuclear 7 Security Unit, Ispra, Italy
}

\begin{abstract}
We present an analysis of the maxima in a large dataset of the beryllium-7 specific activities measured in surface air in Helsinki, Finland, over 25 years (1987-2011), which are stored in the online Radioactivity Environmental Monitoring (REM) database. The maxima are defined as events with the beryllium-7 specific activity above the $95^{\text {th }}$ percentile, which, for the Helsinki data set, equals to $4.82 \cdot 10^{-3} \mathrm{~Bq} \cdot \mathrm{m}^{-3}$. The beryllium-7 specific activity in Helsinki shows a seasonal pattern with the monthly means above $2.00 \cdot 10^{-3} \mathrm{~Bq} \cdot \mathrm{m}^{-3}$ during the warm season (AprilSeptember), and below $2.00 \cdot 10^{-3} \mathrm{~Bq} \cdot \mathrm{m}^{-3}$ during the cold season (October-March). The analysis of the extremes shows that $10 \%$ occurred in the cold season, and these "cold extremes" are analysed in more detail. Amongst the cold extremes, three representative "episodes" are identified. The episodes, which occurred in March 1999, February 2003 and February 2005, show extremely high beryllium-7 specific activities measured over several consecutive days. Anomalies of potential vorticity, sea level pressure and surface temperature, as well as precipitation, over Europe and the Atlantic are investigated. A brief analysis of one cold extreme, classified as "burst" since it was an isolated event surrounded by measurements below the $95^{\text {th }}$ percentile, is also presented in an attempt to find common mechanisms that contribute to both cold extreme episodes and bursts. Scandinavia teleconnection index seems to represent a good indicator of potentially preferential atmospheric conditions that could lead to cold extreme episode occurrences in the Scandinavian region.
\end{abstract}

Key words: Beryllium-7, surface air, maximum concentrations, $P V$, Scandinavia teleconnection index

\section{INTRODUCTION}

Beryllium-7 (half-life 53.22 days), a naturally occurring radionuclide, is produced in the upper troposphere and lower stratosphere (UTLS region) [1], where it attaches to fine aerosols promptly after production [2]-[4]. Its ensuing behaviour in the atmosphere is governed by horizontal and vertical transport and removal mechanisms [5], [6].

The concentration of $7 \mathrm{Be}$ in surface air depends on a number of factors. The shorter the time $7 \mathrm{Be}$ is transported from its point of origin (production altitude) to the Earth's surface, the higher its concentration in surface air. Therefore, fast air subsidence, especially through the tropopause layer, results in a high $7 \mathrm{Be}$ concentration at the surface [7]. Further, the surface $7 \mathrm{Be}$ concentration exhibits a latitudinal dependence such that in Europe, for example, the measurement sites in the south show $\sim 2.5$ higher concentrations than the sites in the north [8]. A clear seasonal cycle in surface $7 \mathrm{Be}$, with the highest concentrations occurring in spring or summer, and the lowest in winter has also been shown [8], [9].

The spring-summer maximum of the 7 Be specific activity in surface air has been attributed to an increase in vertical transport during that season [10], [11] Further, elevated 7 Be surface concentrations have been associated with stratospheric intrusions into the troposphere [10], [12], [13]. However, the existence of extremely high 7 Be concentrations in surface air during the colder half of the year (autumn and winter) have not yet been systematically investigated.

To answer a question whether very high 7Be surface concentrations occur during autumn and winter, we used a large dataset of the $7 \mathrm{Be}$ specific activities in surface air in Helsinki, Finland. This data set, which is a part of the online Radioactivity Environmental Monitoring (REM) Database, contains more than 4000 measurements conducted over 25 years, 1987-2011.

First, the extremely high specific activities, or the extremes, were defined as the maxima in the database, i.e. the measurements higher than the $95^{\text {th }}$ percentile. Then, we looked for the "cold" extremes that occurred during autumn or winter. We separated the cold extremes into "bursts" and "episodes" depending on their persistence. Meteorological conditions preceding and during three cold extreme episodes were analysed in more detail, while only a brief analysis of one burst was performed. However, we made an attempt to find common features that could explain the occurrence of both the cold extreme episodes and bursts.

"The paper was presented at the Fourth International Conference on Radiation and Applications in Various Fields of Research (RAD 2016), Niš, Serbia, 2016.

**jelena.ajtic@vet.bg.ac.rs 


\section{MATERIALS AND METHODS}

\subsection{Datasets}

Measurements of the ${ }^{7} \mathrm{Be}$ specific activity in surface air in Helsinki $\left(60.21^{\circ} \mathrm{N}, 25.06^{\circ} \mathrm{E}\right)$, Finland, are a part of a wider collection of different radionuclides' measurements in a number of environmental sample types, stored in the Radioactivity Environmental Monitoring Database (REMdb). The REMdb is supported by the REM group from the Institute of Transuranium Elements, of the DG Joint Research Centre (JRC). The ${ }^{7} \mathrm{Be}$ database stored in the REMdb is public until 2006, and the access to the data corresponding to the 2007-2011 period can be granted only after explicit request. More details on the REMdb and $7 \mathrm{Be}$ specific activity measurements can be found in [8] and on the REMdb monitoring reports site https://rem.jrc.ec.europa.eu/RemWeb/Reports.aspx.

The Helsinki $7 \mathrm{Be}$ dataset encompasses the measurements performed between 1987 and 2011 . Even though it is not of the longest duration, it is now, due to its high temporal resolution, the largest dataset with more than 4000 measurements. In 1999, the sampling frequency increased from once a week to every day or once in two days.

\section{2. ${ }^{7 B e}$ specific activity in surface air in Helsinki}

The annual cycle of the $7 \mathrm{Be}$ specific activity in surface air in Helsinki, 1987-2011, is given in Fig. 1. The monthly mean concentrations showed a pattern with values higher than $2.00 \cdot 10^{-3} \mathrm{~Bq} \cdot \mathrm{m}^{-3}$ over AprilSeptember. The other, colder, half of the year, October-March, was characterised by lower $7 \mathrm{Be}$ surface concentrations. This half of the year was named "cold season".

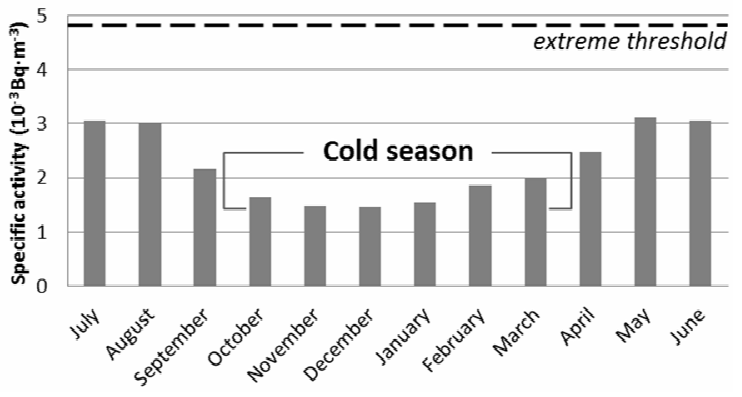

Figure 1. Monthly mean 7Be specific activities in surface air in Helsinki. The dashed line indicates the $95^{\text {th }}$ percentile $\left(4.82 \cdot 10^{-3} \mathrm{~Bq} \cdot \mathrm{m}^{-3}\right)$ which represents the threshold for an extreme

The extremely high specific activities, or the extremes, in the $7 \mathrm{Be}$ dataset were identified as the maxima above the $95^{\text {th }}$ percentile. Specifically, this threshold was $4.82 \cdot 10^{-3} \mathrm{~Bq} \cdot \mathrm{m}^{-3}$. The extremes that occurred during the cold season were then termed "cold extremes". The cold extremes were further divided into two classes depending on their persistence. If a cold event was also detected in a preceding or subsequent measurement, i.e. if at least two consecutive measurements noted an extreme, they were grouped in an "episode". In contrast, if a cold extreme was an isolated event surrounded by measurements below the $95^{\text {th }}$ percentile, it was termed "burst". The search for the extremes was performed through the entire set of the $7 \mathrm{Be}$ measurements.

Apart from the temporal persistence of the cold extremes, their spatial extent was also analysed by searching for concomitant extremes in the surrounding stations. The surrounding stations were selected from the REMdb provided they satisfied two conditions: their total number of measurements was larger than 400 , and the stations were in a relative vicinity of Helsinki. Five stations satisfied the set criteria: Ivalo $\left(60.64{ }^{\circ} \mathrm{N}, 27.57^{\circ} \mathrm{E}\right)$, Umea $\left(63.85^{\circ} \mathrm{N}, 20.34^{\circ} \mathrm{E}\right)$, Kista $\left(59.40^{\circ} \mathrm{N}, 17.93{ }^{\circ} \mathrm{E}\right)$, Harku (59.39 $\left.{ }^{\circ} \mathrm{N}, 24.58^{\circ} \mathrm{E}\right)$, and Risoe $\left(55.69{ }^{\circ} \mathrm{N}, 12.10{ }^{\circ} \mathrm{E}\right)$. The extreme threshold in those stations was set to either their $95^{\text {th }}$ percentile or the $95^{\text {th }}$ percentile for Helsinki - the lower of the two.

\subsection{Circulation pattern analysis}

Meteorological conditions over Europe and the North Atlantic were analysed for extended periods covering the cold extreme episodes.

Potential vorticity (PV) anomaly at the $300 \mathrm{hPa}$ isobaric level was firstly calculated. The PV anomaly could be an indicator of a location wherein an intrusion of stratospheric air brings 7 Be-rich air into the troposphere [14], [15]. The PV anomaly was calculated for a three-day period preceding each cold episode. The duration of the preceding period was chosen on the following premises: the stratosphere-to-troposphere intrusion occurs before a $7 \mathrm{Be}$ extreme is detected in surface air; the time in which the $7 \mathrm{Be}$ surface concentration responds to changes in tropopause height is three days [16]. The PV anomaly was calculated with respect to a long-term climatology, defined as a long-term (covering 1981-2010) PV mean value during the cold episode days, five preceding and five subsequent days. This five-day window was introduced following a procedure used in long-term climatology calculations for each day of the year [17].

Secondly, sea level pressure (SLP) and surface temperature (T) anomalies were calculated in the same manner, with one difference - the investigated periods covered not only the three days prior to the episode, but also the whole duration of the episode. Hence, the influence of meteorological conditions during each episode was taken into consideration. We chose SLP as an indicator of subsidence motion in the troposphere, whose importance in the $7 \mathrm{Be}$ abundance has been shown [10]. Positive pressure anomaly indicates anticyclonic atmospheric flow in which subsidence is a part of its dynamics. Positive correlation between the ${ }^{7} \mathrm{Be}$ surface concentration and temperature, reported in [3], [11], [18], was the reasoning behind the inclusion of the temperature field into the analysis. Furthermore, as subsidence leads to adiabatic heating of air, high positive temperature anomaly at the surface may imply transport of air from higher to lower altitudes.

Finally, we looked into the total precipitation accumulation (RR) during each episode, since we expected a dry period to prevent ${ }^{7} \mathrm{Be}$ washout from the atmosphere and thus facilitate its accumulation over a prolonged period. The potential vorticity, sea level pressure and temperature anomalies were calculated using the NCEP/NCAR reanalysis [19], and the total precipitation accumulation was calculated using the EOBS data set [20]. 


\section{RESULTS AND DISCUSSION}

In the Helsinki data set, 212 extremes were identified, wherein 21 (10\%) occurred during the cold season. Table 1 summarises the cold extremes and their spatial extent.

Table 1. Cold extremes, their classification, and notes on the spatial extent of their occurrence

\begin{tabular}{|c|c|c|}
\hline $\begin{array}{c}\text { Date } \\
\text { (dd/mm/yyyy) }\end{array}$ & Class & $\begin{array}{l}\text { Detected in surrounding } \\
\text { stations } \\
\end{array}$ \\
\hline $\begin{array}{l}18 / 11 / 1993 \\
22 / 11 / 1993\end{array}$ & episode & $\begin{array}{l}\text { Risoe on } 16 / 11 \\
\text { Ivalo on } 29 / 11\end{array}$ \\
\hline 23/01/1995 & burst & Ivalo 23/01 \\
\hline 17/03/1995 & burst & Ivalo $20 / 03$ \\
\hline $\begin{array}{l}12 / 03 / 1999 \\
13 / 03 / 1999 \\
14 / 03 / 1999 \\
15 / 03 / 1999 \\
16 / 03 / 1999 \\
20 / 03 / 1999\end{array}$ & episode $^{1}$ & \\
\hline $11 / 10 / 2002$ & burst & \\
\hline $\begin{array}{l}30 / 11 / 2002 \\
01 / 12 / 2002\end{array}$ & episode $^{*}$ & \\
\hline $\begin{array}{l}20 / 02 / 2003 \\
21 / 02 / 2003 \\
22 / 02 / 2003\end{array}$ & episode $^{2}$ & $\begin{array}{c}\text { Ivalo on 23/o2 } \\
\text { Umea and Risoe on 24/o2 }\end{array}$ \\
\hline $\begin{array}{l}08 / 02 / 2005 \\
09 / 02 / 2005 \\
10 / 02 / 2005\end{array}$ & episode $^{3}$ & \\
\hline $02 / 11 / 2005$ & burst & Harku 06/11 \\
\hline $10 / 10 / 2010$ & burst $^{\#}$ & $\begin{array}{l}\text { Kista on } 10 / 10 \\
\text { Risoe on } 11 / 10\end{array}$ \\
\hline
\end{tabular}

\subsection{Cold extreme episodes}

Within the cold extremes, five episodes were observed. The first episode occurred in November 1993 , in the period when the sampling frequency was approximately once a week. This event with an elevated 7Be surface concentration was also evident in Risoe and Ivalo (Tab. 1). The episode marked with the asterisk sign $(*)$ seems to have lasted longer than two days, as four subsequent measurements after 01/12/2002, showed the specific activities higher than $4.00 \cdot 10^{-3}$ $\mathrm{Bq} \cdot \mathrm{m}^{-3}$ (but below the $95^{\text {th }}$ percentile).

The three episodes marked with superscripts 1-3 (Tab. 1) were detected in more than two consecutive measurements, and they were analysed in more detail. The anomalies of PV, SLP and T, as well as RR for the three extreme episodes, are shown in Figs. 2-4.

We found the following common features in the cold extreme episodes:

1) a positive potential vorticity anomaly west of Helsinki, which was pronounced (higher than 3 PVU; $1 \mathrm{PVU}=10^{-6} \mathrm{~m}^{2} \mathrm{~s}^{-1} \mathrm{~K} \mathrm{~kg}^{-1}$ ) prior to episodes 1 and 2, and which could point to a stratospheric intrusion and the subsequent eastward transport of 7 Be-rich air towards Helsinki;

2) a high pressure anomaly over Scandinavia, with an associated westward low; and

3) dry conditions during the episodes.

These results agree well with the anticyclonic flow and no precipitation that were associated with high $7 \mathrm{Be}$ surface concentrations recorded at a high-elevation measurement site in the Alps [21]. The surface temperature, however, showed a positive anomaly over Scandinavia in episodes 2 and 3. Only during episode 1, the temperature anomaly was clearly negative in the wider Helsinki region.
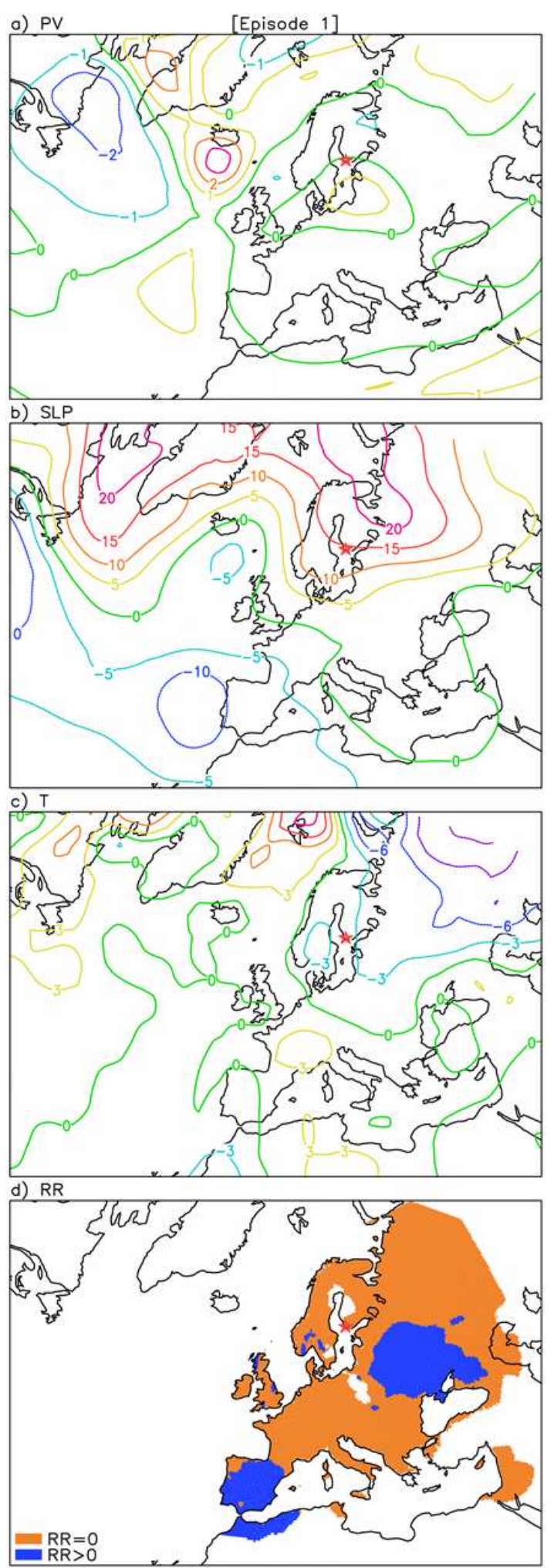

Figure 2. Meteorological conditions over Europe and the Atlantic during the extreme episode 12-16/o3/1999: a) potential vorticity anomaly; b) sea level pressure anomaly; c) 
J. Ajtić et al., Analysis of Extreme Beryllium-7 Specific Activities..., Rad. Applic., 2016, 1, 3, 216-221 surface air temperature anomaly; and d) total accumulation
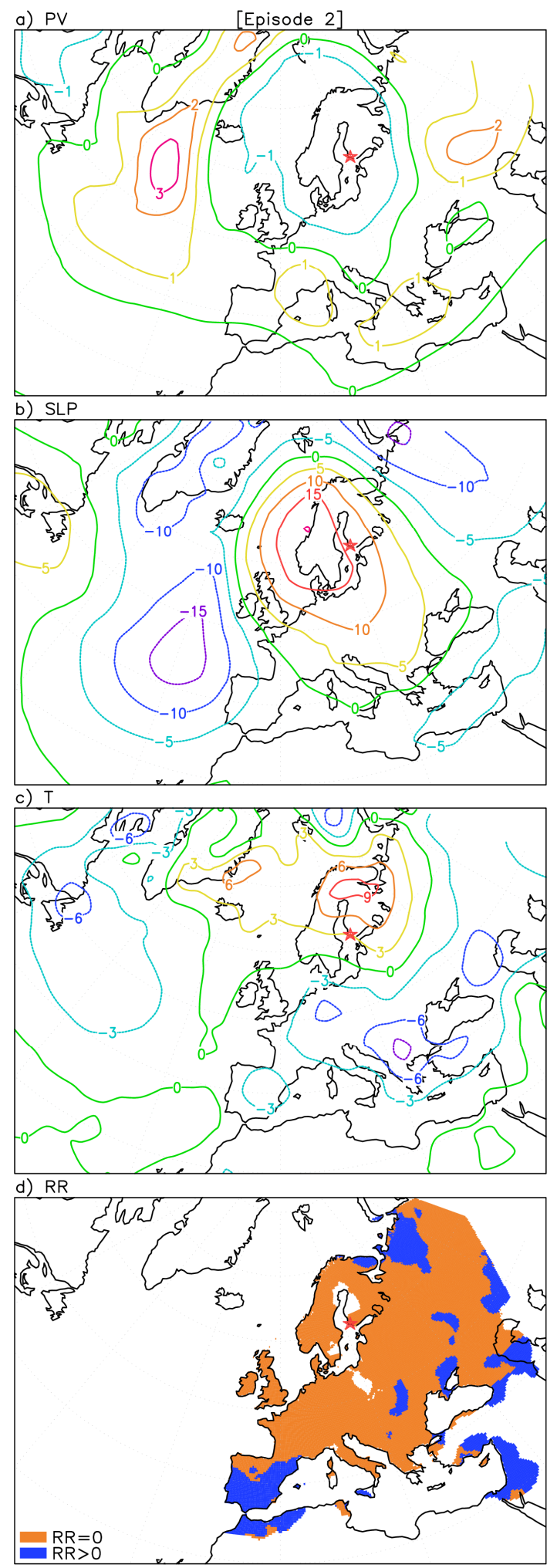

precipitation. The red star denotes Helsinki, Finland

Figure 3. Same as Fig. 2 but for the extreme episode from 20 to 22 February 2003

This temperature anomaly finding does not fully agree with our initial premise that an anticyclonic atmospheric flow, with a positive surface pressure

anomaly and an associated subsidence, leads to a positive temperature anomaly. Reasons for this difference during episode 1 could probably be assessed in a more extensive analysis of atmospheric conditions.
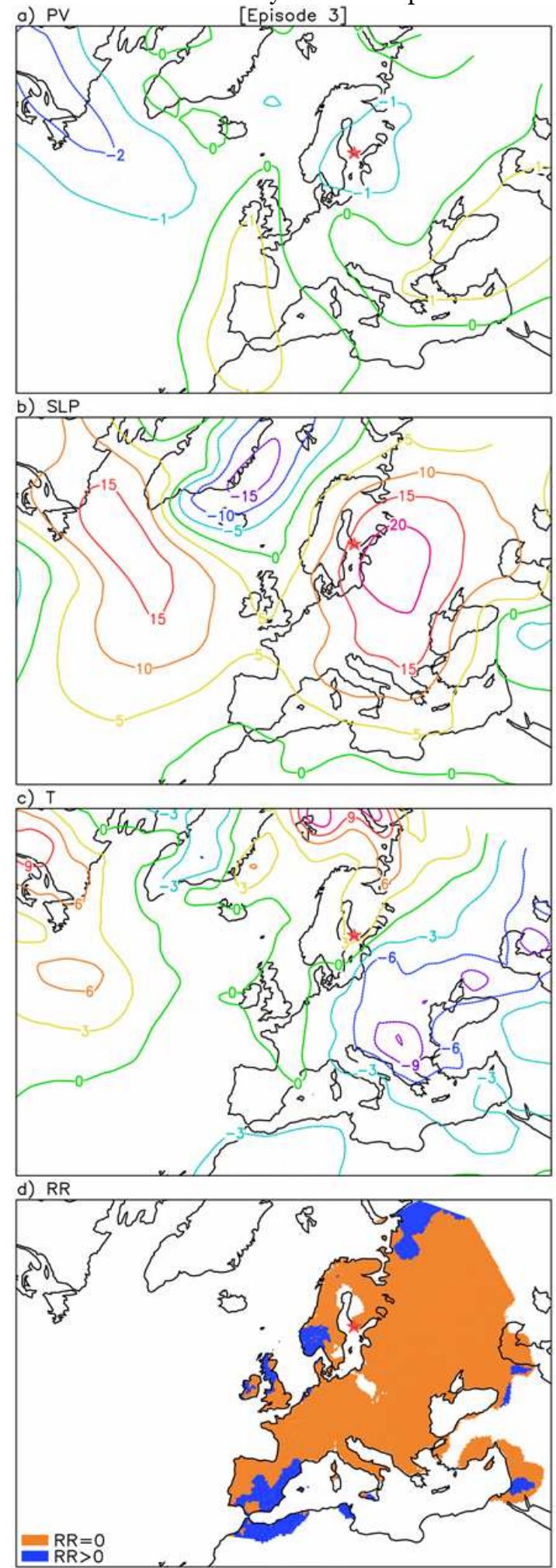

Figure 4. Same as Fig. 2 but for the extreme episode from 08 to 10 February 2005

Since the observed conditions during the cold episodes resembled atmospheric conditions associated with the January loading pattern of the Scandinavia 
(SCAND) teleconnection index [22], we further looked into its values during the cold extreme episodes. Fig. 5 gives SCAND for the cold season months over 19872011 (ftp://ftp.cpc.ncep.noaa.gov accessed 22 February 2016).

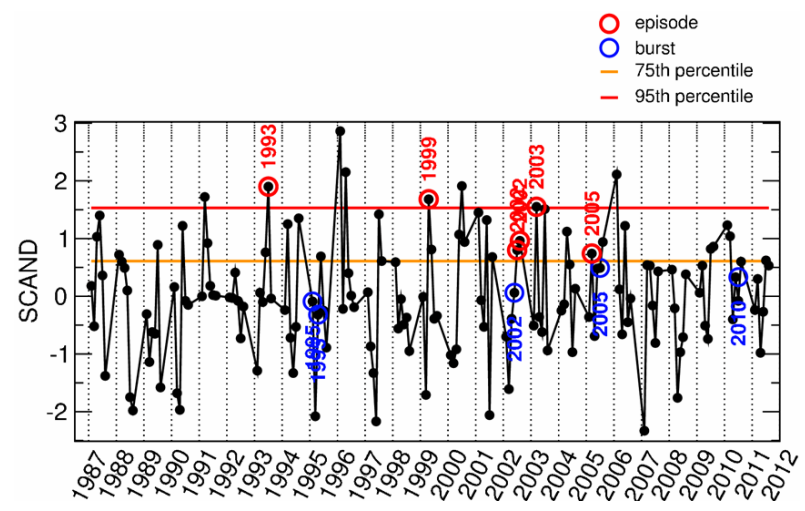

Figure 5. Monthly values of the SCAND index (black). In each year, six values, representing the cold months, are given. Red and blue circles annotate months when the cold extreme episodes and bursts, respectively, were recorded. Orange and red lines are the $75^{\text {th }}$ and $95^{\text {th }}$ percentile thresholds for the SCAND distribution

All months during which the cold extreme episodes were observed (Tab. 1) showed the SCAND index over the $75^{\text {th }}$ percentile, and for episodes 1 and 2 , the SCAND index was above the $95^{\text {th }}$ percentile. It is worth noting that in both January and March 1996, when SCAND index was extremely high (Fig. 5), there was one measurement per month with the $7 \mathrm{Be}$ specific activity larger than $4.00 \cdot 10^{-3} \mathrm{~Bq} \cdot \mathrm{m}^{-3}$, and the monthly mean activities were above $2.00 \cdot 10^{-3} \mathrm{~Bq} \cdot \mathrm{m}^{-3}$. This relation, however, was not repeated in other cold months with high SCAND.

\subsection{Cold extreme bursts}

The two bursts detected in January and March 1995 (Tab. 1) may not necessarily fall in that category, as sampling was performed only once a week. Those bursts, therefore, might have been of a longer duration.

The bursts that occurred after 1999, when the sampling frequency was increased, probably indicate sudden and short-lasting favourable atmospheric conditions that allowed a fast influx of $7 \mathrm{Be}$, and a similarly fast decline in its surface concentration. The inflow of $7 \mathrm{Be}$-rich air can be a result of either direct or indirect transport from the UTLS [21]. The former consists of a fast downward motion, while the latter includes a somewhat slower motion, which allows a certain degree of mixing between the stratospheric and tropospheric air. In a cold extreme burst, air subsidence could be followed by horizontal transport, with a fast resulting transport of air so that extremely elevated $7 \mathrm{Be}$ concentrations remain its signature. A rapid decline in the $7 \mathrm{Be}$ concentration could again be achieved via transport, or removal through wet deposition.

The favourable conditions, although only transient, were not necessarily constricted to the Helsinki region. In fact, since some of bursts were detected on the same day in the surrounding stations (Tab. 1), the favourable conditions could be of mesoscale extent.

The temporal evolution of the ${ }^{7 B e}$ surface concentration and precipitation around the date of the burst ${ }^{\#}$ (Tab. 1) is given in Fig. 6. In this burst, the rise towards the extreme on 10/10 took the preceding week, and although transport was responsible for the inflow of $7 \mathrm{Be}$-rich air, the surface build-up of $7 \mathrm{Be}$ was aided by a dry spell that lasted for 18 days (23/09-10/10). Removal of $7 \mathrm{Be}$ from surface air, which led to a sharp drop in concentration, was at least partly facilitated by precipitation on 11/10. The importance of dry conditions in $7 \mathrm{Be}$ accumulation, shown here in both the episodes and bursts, has been observed before [9], [10].

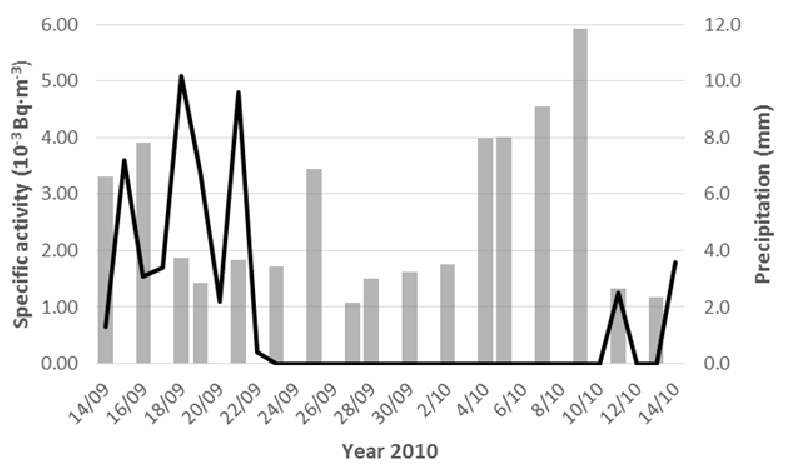

Figure 6. Specific activity of 7Be (grey bars) and precipitation (black line) from mid-September to mid-October 2010

Similarly to the aforementioned episode*, this burst ${ }^{\#}$ could be classified as a less pronounced episode, since four consecutive measurements between 04 and 10 October 2010 showed an increased $7 \mathrm{Be}$ surface concentration (around $4.00 \cdot 10^{-3} \mathrm{~Bq} \cdot \mathrm{m}^{-3}$ and higher).

However, this classification would not be supported by the SCAND index (if it were taken as an indicator of a cold extreme episode), since it was below the $75^{\text {th }}$ percentile (Fig. 5). Still, SCAND showed another similarity with the $7 \mathrm{Be}$ extremes - in the 2002, 2005, and 2010 bursts (Tab. 1), the SCAND index was positive, and in fact, close to the $75^{\text {th }}$ percentile in the latter two bursts. In January and March 1995, however, a negative SCAND index accompanied the bursts (Fig. 5).

Previous studies have shown that the long-term variations in the $7 \mathrm{Be}$ surface concentration in the Scandinavian region are influenced by the North Atlantic Oscillation and Atlantic Multidecadal Oscillation teleconnection indices [23], [24]. However, there have been no analyses of the SCAND influence on the $7 \mathrm{Be}$ surface concentrations, especially its correlation with extremely high ${ }^{7} \mathrm{Be}$ concentrations.

\section{CONCLUSION}

Our results showed that although rarely, only $10 \%$ of the total measurements above the $95^{\text {th }}$ percentile, extreme $7 \mathrm{Be}$ concentrations in surface air do occur during the cold half of the year. Some of these events were brief, noted in an isolated measurement, while others lasted longer, and were detected in several 
J. Ajtić et al., Analysis of Extreme Beryllium-7 Specific Activities..., Rad. Applic., 2016, 1, 3, 216-221

consecutive measurements. The investigated atmospheric conditions prior to and during these extreme events, indicated a few common features, which were encompassed by a positive, and sometimes extremely high, SCAND teleconnection index. Therefore, the SCAND index could be regarded as a potential predictor of cold extreme events in the Scandinavian region. A better understanding of dynamics leading to an extreme ${ }^{7} \mathrm{Be}$ event could result from this novel finding.

Acknowledgement: The paper is a part of the research done within the project "Climate changes and their influence on the environment: impacts, adaptation and mitigation" (No. 43007) financed by the Ministry of Education, Science and Technological Development of the Republic of Serbia (2011-2016). The authors would like to thank the REM group for the provision of the beryllium-7 specific activity measurements from the REM database (REMdb at the Institute of Transuranium Elements, REM group, DJ JRC Ispra site, European Commission). The authors also acknowledge the E-OBS dataset from the EU-FP6 project ENSEMBLES (http://ensembleseu.metoffice.com) and the data providers in the ECA\&D project (http://www.ecad.eu).

\section{REFERENCES}

1. D. Lal and B. Peters, "Cosmic ray produced radioactivity on the earth," in Cosmic Rays II, K. Sitte, Ed., Berlin, Heidelberg, Germany: Springer, 1967, pp 551-612

2. D. M. Koch, D. J. Jacob and W. C. Graustein, "Vertical transport of tropospheric aerosols as indicated by $7 \mathrm{Be}$ and ${ }^{210} \mathrm{~Pb}$ in a chemical tracer model," J. Geophys. Res., vol. 101, pp. 18651-18666, 1996.

3. C. Dueñas, M. C. Fernández, J. Carretero, E. Liger and S. Cañete, "Long-term variation of the concentrations of long-lived Rn descendants and cosmogenic $7 \mathrm{Be}$ and determination of the MRT of aerosols," Atmos. Environ., vol. 38, pp. 1291-1301, March 2004.

4. U. Heikkilä, J. Beer and V. Alfimov, "Beryllium-10 and beryllium-7 in precipitation in Dübendorf (440 m) and at Jungfraujoch (3580 m), Switzerland (1998-2005)," J. Geophys. Res., vol. 113, 2008.

5. E. Gerasopoulos, C. S. Zerefos, C. Papastefanou, P. Zanis and K. O'Brien, "Low-frequency variability of beryllium-7 surface concentrations over the Eastern Mediterranean," Atmos. Environ., vol. 37, pp. 1745$1756,2003$.

6. P. Cristofanelli et al., "A 6-year analysis of stratospheric intrusions and their influence on ozone at Mt. Cimone (2165 m above sea level)," J. Geophys. Res., vol. 111, no. D3, 2006.

7. P. Zanis et al., "An estimate of the impact of stratosphere-to-troposphere transport (STT) on the lower free tropospheric ozone over the Alps using ${ }^{10} \mathrm{Be}$ and 7Be measurements," J. Geophys. Res., vol. 108, no. D12, 2003.

8. M. A. Hernández-Ceballos et al., "A climatology of 7Be in surface air in European Union," J. Environ. Radioact., vol. 141, pp. 62-70, 2015.
9. J. Ajtić, D. Todorović, J. Nikolić and V. Djurdjević, "A multi-year study of radioactivity in surface air and its relation to climate variables in Belgrade, Serbia," Nucl. Technol. Radiat., vol. 28, pp. 381-388, 2013.

10. E. Gerasopoulos et al., "A climatology of $7 \mathrm{Be}$ at four high-altitude stations at the Alps and the Northern Apennines," Atmos. Environ., vol. 35, pp. 6347-6360, 2001.

11. A. Ioannidou, M. Manolopoulou and C. Papastefanou, "Temporal changes of $7 \mathrm{Be}$ and ${ }^{210} \mathrm{~Pb}$ concentrations in surface air at temperate latitudes $\left(40^{\circ} \mathrm{N}\right),{ }^{\circ}$ Appl. Radiat. Isot., vol. 63, pp. 277-284, 2005.

12. P. Bonasoni et al., "Stratospheric ozone intrusion episodes recorded at Mt. Cimone during the VOTALP project: case studies," Atmos. Environ., vol. 34, pp. 1355-1365, 2000.

13. P. Zanis et al., "Forecast, observation and modelling of a deep stratospheric intrusion event over Europe," Atmos. Chem. Phys., vol. 3, pp. 763-777, 2003.

14. E. F. Danielsen, "Stratospheric-tropospheric exchange based on radioactivity, ozone and potential vorticity", $J$. Atmos. Sci., vol. 25, pp. 502-518, 1968.

15. P. Cristofanelli et al., "Stratospheric intrusion index (SI') from baseline measurement data," Theor. Appl. Climatol., vol. 97, pp. 317-325, 2009.

16. A. Ioannidou, A. Vasileiadis and D. Melas, "Time lag between the tropopause height and $7 \mathrm{Be}$ activity concentrations on surface air," J. Environ. Radioact., vol. 129, pp. 80-85, 2014.

17. World Meteorological Organization. (Geneva, 2009). WCDMP-No. 72, Guidelines on Analysis of extremes in a changing climate in support of informed decisions for adaptation

18. M. K. Pham, M. Betti, H. Nies and P. P. Povinec, "Temporal changes of $7 \mathrm{Be},{ }^{137 \mathrm{Cs}}$ and ${ }^{210} \mathrm{~Pb}$ activity concentrations in surface air at Monaco and their correlation with meteorological parameters," $J$. Environ. Radioact., vol. 102, pp. 1045-1054, November 2011.

19. E. Kalnay et al., "The NCEP/NCAR 40-Year Reanalysis Project," Bull. Am. Meteorol. Soc., vol. 77, pp. 437-471, March 1996.

20. M. R. Haylock et al., "A European daily high-resolution gridded dataset of surface temperature and precipitation," J. Geophys. Res., vol. 113, D20119, 2008.

21. P. Zanis, E. Schuepbach, H. W. Gäggeler, S. Hübener and L. Tobler, "Factors controlling beryllium-7 at Jungfraujoch in Switzerland," Tellus B, vol. 51, pp. 789805, September 1999.

22. A. G. Barnston and R. E. Livezey, "Classification, seasonality and persistence of low-frequency atmospheric circulation patterns," Mon. Weather Rev., vol. 115, pp. 1083-1126, June 1987.

23. A.-P. Leppänen et al., "Cosmogenic $7 \mathrm{Be}$ in air: A complex mixture of production and transport," $J$. Atmos. Sol. Terr. Phys., vol. 72, pp. 1036-1043, August 2010.

24. A.-P. Leppänen, I. G. Usoskin, G. A. Kovaltsov and J. Paatero, "Cosmogenic $7 \mathrm{Be}$ and ${ }^{22} \mathrm{Na}$ in Finland: Production, observed periodicities and the connection to climatic phenomena," J. Atmos. Sol. Terr. Phys., vol. 74, pp. 164-180, January 2012. 